\title{
Twenty-Five Years of Paradox in Plant-Herbivore Interactions and "Sustainable" Grazing Management
}

\author{
By Frederick D. Provenza
}

In his 1982 book The Turning Point: Science, Society, and the Rising Culture, Fritjof Capra makes the following observations concerning paradox in physics:

"In the twentieth century, physicists faced, for the first time, a serious challenge to their ability to understand the universe. Every time they asked nature a question in an atomic experiment, nature answered with a paradox, and the more they tried to clarify the situation, the sharper the paradoxes became. In their struggle to grasp this new reality, scientists became painfully aware that their basic concepts, their language, and their whole way of thinking were inadequate to describe atomic phenomena... It took physicists a long time to accept the fact that the paradoxes they encountered are an essential aspect of atomic physics... Once this was perceived, the physicists began to learn to ask the right questions and to avoid contradictions....and finally they found the precise and consistent mathematical formulation of [quantum] theory... Even after the mathematical formulation of quantum theory was completed, its conceptual framework was by no means easy to accept. Its effect on the physicists' view of reality was truly shattering. The new physics necessitated profound changes in concepts of space, time, matter, object, and cause and effect; and because these concepts are so fundamental to our way of experiencing the world, their transformation came as a great shock."

In a similar way, the field of plant-herbivore interactions has seen its share of paradoxes during the past 25 years. They arise from our inability to fully appreciate the complexities of the phenomena we study, and through their reconciliation, we ultimate- ly improve our understanding of principles and processes $(43,45)$. These paradoxes continue to highlight the dynamic and interconnected nature of reality, and they have profound implications for understanding plant-herbivore interactions and for managing grazing $(39,40)$.

In this article, I discuss our evolving understanding of plant-herbivore interactions and touch on some implications for management. I conclude with the paradox that sustainable grazing management sustainable anything - is an illusion brought about by our inability to accept the true nature of reality. Our attempts to cling to fixed forms - ecologically, socially, and economically - ignore the obvious: the only constant in life is change. In the process of exploiting existing niches, life creates new niches from death comes life and endless transformations.

All things - including suites of plants, herbivores, and the people who manage them - enjoy their moment in the sun only to be ushered off by the next suite of participants in the game. Ironically, when people of disparate backgrounds and values cooperate, we greatly expand the diversity of options upon which to act, thereby increasing the likelihood of prolonging and enjoying our moment in the sun.

\section{Resolving Paradoxes in Plant-Herbivore Interactions}

Plant Structure - A major advance in our appreciation of plant-herbivore interactions came from research to determine how the structure of a plant influences rates of food intake and preference (31). This work, which began over 30 years ago, shows 
that at too low or too high levels of plant biomass, rates of nutrient intake are reduced. Intake is influenced by three factors: bite size, bite rate, and grazing time (intake $=$ bite size $\mathrm{x}$ bite rate $\mathrm{x}$ grazing time). Intake rate is most sensitive to bite size - too little or too much plant biomass diminishes bite size, and either increases (too little forage) or decreases (too much forage) bite rate and grazing time, all of which can diminish animal performance.

These findings caused researchers to conclude that, all things being equal, herbivores should prefer plants that encourage high rates of intake. But from this work came a paradox: If preference was merely a matter of plant structure, why then did herbivores often eat plant species and parts that did not maximize rates of intake $(28,64)$ ?

Plant Primary Chemistry-A partial resolution of this paradox came from research, beginning in the late 1960's, that was devoted to assessing the botanical and chemical composition of the diets of herbivores. These studies showed that herbivores eat a diverse array of plant species - as many as 100 species have been recorded in studies of diets - but they also showed that the bulk of a meal normally contains less than 10 species, typically as few as 3 to 5 species. These efforts also showed that herbivores select diets more nutritious than those we as researchers can pluck by hand. Hence, not only high rates of intake, but high rates of nutrient intake, influence food selection by herbivores.

From such studies, there was evidence that herbivores are nutritionally wise, but we were unable to comprehend how that might be possible, especially given our growing understanding of the immense complexities of biochemistry and nutrition (57). To further muddle the waters, herbivores don't always select the most nutritious foods, which certainly supports the alternative hypothesis that they lack nutritional wisdom. Domestic goats, for instance, prefer older growth to current season's growth from the shrub blackbrush, even though current season's growth is much more nutritious than older growth (41). Similar observations were noted for fishes, birds, and mammals $(7,22,32,64)$. So, out of this work, too, arose a paradox: If herbivores are nutritionally wise, and if preference is simply a matter of nutrients, why then do they sometimes prefer less nutritious plant species and parts?
Plant Secondary Chemistry - Over a 20 -year period beginning in the early 1970's there grew an awareness of the importance of so-called secondary plant metabolites (48). Scientists understood the roles of primary compounds such as nitrogen, phosphorus, and potassium, but during this era they discovered that a vast array of interactions in terrestrial and aquatic ecosystems are mediated by secondary compounds formerly thought to be waste products of plant metabolism (47). They also came to better understand how environmental factors - nutrients, water, light - influence the evolution (13) and phenotypic expression (8) of secondary compounds, and how secondary compounds influence herbivores.

Plants that produce compounds that can quickly induce satiety in foragers stand a better chance of surviving. Most secondary compounds limit how much of a particular species an herbivore can eat, which spreads the load of herbivory across many species in a plant assemblage $(17,18)$. Thus, where once we thought only poisonous plants - those species that for one reason or another are a problem for herbivores (42) - contain compounds that are potentially toxic, there is increasing awareness that all plants, including garden vegetables, contain toxins that limit intake (46).

Nevertheless, herbivores are rarely poisoned because they self-regulate, through postingestive feedback from toxins $(36,38)$, their intake of plants. Thus, to obtain needed nutrients, herbivores must eat a variety of plant species that contain different kinds of toxins. In principle, herbivores should be able to do so because foods with different kinds of toxins produce different effects in the body and they are detoxified by different mechanisms $(17,18,46)$.

The discovery of the importance of secondary metabolites, while resolving one contradiction, led to others: If palatability was mediated by secondary metabolites, why then did herbivores prefer plant species and parts high in secondary metabolites on some occasions $(36,38)$ ?

Plant Biochemical Diversity, Individuality, and Herbivore Experience - Nowadays we are coming to appreciate the fact that the amount of toxin an animal can ingest depends on the kinds and amounts of nutrients and toxins in the forages on offer $(17,46)$. Nutrients and toxins both cause animals to satiate, and excesses of nutrients, nutrient imbalances, and toxins all limit food intake. Thus, individuals can better meet their needs for nutrients 
and regulate their intake of toxins when offered a variety of foods that differ in nutrients and toxins than when constrained to a single food, even if that food is "nutritionally balanced."

The rate at which toxin-containing foods can be eaten likely depends on how quickly toxins can be detoxified and eliminated from the body (17). The general mechanism of detoxification involves conversion of more toxic lipophilic compounds into less toxic water-soluble compounds that can be excreted in the urine. These transformations require nutrients such as energy, protein, and water. Many toxins are excreted as conjugated amino acids, glucuronic acid, or sulfate, and the creation of these compounds yields organic acids that can disrupt acid-base balance and deplete amino acids and glucose. Thus, detoxification processes reduce the amount of protein and energy that otherwise would be available for animal maintenance and production.

Supplemental energy and protein increase the ability of animals to eat foods that contain toxins as diverse as lithium chloride, menthol, terpenes, tannins, and saponins (46). Conversely, low levels of sodium in the diet restrict the amount of toxins an animal can ingest, and the sodium-depleting effects of many toxins may deter herbivores from eating plants low in sodium. Thus, supplemental nutrients help animals cope with toxins and reduce the time they require to adapt to toxins. Supplements offer the potential to increase the intake of plants that are habitually avoided, and that may therefore reduce biodiversity by coming to dominate landscapes (44).

Food intake and preference also depend on differences in how individual animals are built morphologically and how they function physiologically, and even among closely related animals significant variation is common in the need for nutrients and the ability to cope with toxins (46). Thus, feeding and grazing practices that allow the individuality of animals to be expressed are likely to improve performance of the herd. Transient food aversions, due to eating the same food too frequently or in too large amounts, compound the inefficiency of singlefood diets - whether in confinement, on pastures, or on rangelands - by depressing intake among individual animals, even if they are suited "on average" to that nutrient or toxin profile (38).

Finally, learning plays a key role in an animal's propensity to eat foods that differ in amounts of nu- trients and toxins $(37,46)$. When herbivores are allowed to eat only the most preferred plants, they are not likely to learn to mix foods high in nutrients with foods that contain toxins. Conversely, herbivores encouraged to eat all plants in an area are more likely to learn to eat mixes of plants that mitigate toxicity. Experienced animals who have learned to eat a variety of foods that differ in nutrients and toxins do so even when nutritious alternatives are available, whereas naive animals familiar only with the nutritious alternatives eat only that subset of familiar foods $(40,58)$.

Sadly, we know very little about how herbivores might also learn to use secondary compounds for health and medicinal benefits (16). While much remains to be learned, herbivores can learn to use medicines to attenuate the aversive effects of acidosis as well as tannin and terpene toxicosis $(16,44)$. They also select diets that provide necessary amounts of energy and protein, synchronize the supply of energy and protein, balance supplies of macronutrients and toxins, and contain different kinds of complementary toxins $(36,44,45,46)$. All of these examples show that herbivores can learn associations among nutrients, toxins, and medicines.

\section{Implications for Grazing Management}

Coincident with our growing understanding of plant-herbivore interactions are ever-evolving views of how plants and herbivores should be managed to sustain productivity of soils, plants, herbivores, and people (5). Early attempts, such as rest-rotation grazing, addressed the needs of plants with less regard for herbivores, while forms of deferred rotational grazing attempted to better balance the needs of plants and herbivores. These practices focused on moderate utilization of key plant species and attempted to obtain more uniform dispersion of animals across landscapes in order to maintain range condition and carrying capacity (54).

These efforts were a first and important attempt to manage grazing in ways that recognize the needs of plants and herbivores. Nonetheless, there was paradox: If these systems were improving landscapes, why were the numbers of livestock on rangelands being reduced? Why, even with reductions in numbers, were riparian areas still being degraded, while uplands were often underutilized? Why, more general- 
ly, were rangelands "understocked and overgrazed?"

Holistic Resource Management - For the past 25 years, an emphasis on the interrelated nature of systems - biophysical, social, economic - has led to more holistic forms of decision making concerning management $(19,20,49)$. As regards grazing, both short-duration and management-intensive approaches emphasize the need to intensify management while considering biophysical, social, and economic facets of systems.

Both have come to rely heavily on control of grazing, with the use of new technologies involving various forms of electric fencing, to increase diet and habitat breadth by controlling time (how long pastures are grazed), timing (when pastures are grazed), and location (where) of grazing. In so doing, they attempt to better meet the needs of plants, thereby enhancing energy flow, nutrient and water cycling. As well, they emphasize enhanced animal performance, obtained by maximizing rates of intake of nutrients from plants maintained in vegetative stages of growth.

While there is considerable controversy and ongoing debate about the merits of short-duration and management-intensive approaches to grazing management $(23,34)$, these endeavors have made vast strides to integrate the science of plant-herbivore interactions with the art of grazing management across landscapes, and to influence people to operate in holistic ways that consider ecological, economic, and social facets of management.

Despite growing understanding of the science of plant-herbivore interactions and the art of grazing management, global, regional, and local paradoxes remain. Why are extensively and intensively managed systems deteriorating in some cases and improving in others? Why the marked increase in weeds during the past 25 years? Why has our emphasis on high rates of livestock gain led to less productive ecosystems (26)? More generally, why do narrowly focused production systems from feedlots (35) to rangelands (2) ultimately lead to "less resilient and more vulnerable ecosystems, more rigid and unresponsive management agencies, and more dependent societies" (26)?

Strands in a Web of Culture, Ecology, and Economy - Barring sweeping changes in our own behavior, in attempting to manage grazing we come to cultural paradigms and paradoxes that may be in- surmountable. For example, even though grazing can enhance plant diversity in sagebrush-steppe ecosystems (4), diversity has declined during the past century as toxin-containing woody plants such as sagebrush (Artemisia spp.) and juniper (Juniperus spp.) have come to dominate over 39 million hectares of land in the Western U.S. (60).

Domination by sagebrush is a result of interactions among social, economic, and ecological strands in a tightly woven web that influences how ecosystems are managed. Sagebrush dominance is due in part to the increase in the abundance of grazers such as cattle and elk relative to mixed feeders and browsers such as sheep, goats, deer, and antelope $(9,24)$. A combination of foragers can maintain more diverse mixtures of plants, and the increase in abundance of shrubs such as sagebrush, and forbs such as leafy spurge and knapweed, is no doubt more than coincidentally related to the decline in goats and sheep, which reflects our culturally conditioned preferences for cattle and beef.

To exacerbate matters, traditional grazing management likely has conditioned the palates of grazers who have learned to prefer grasses and forbs and to avoid shrubs $(40,46,58)$. Their preferences have reduced fine fuels for fires, and along with policies of fire suppression during the past century, have helped to increase the abundance of sagebrush relative to herbs thereby setting the stage for severe fire storms that further reduce biodiversity of sagebrush-steppe $(61,62)$.

The discovery of the importance of interactions between selective herbivory and fire, while unraveling one knot, led to another: Why under some conditions is management to enhance and maintain the abundance of key species of grasses and forbs successful, while in other situations plants such as sagebrush increase in abundance despite our best attempts to manage grazing? More generally, how do history, necessity, and chance influence the evolution of ecosystems $(43,45,58)$ ?

Escape Thresholds: History, Necessity, and Chance - Many grazing systems confine livestock to areas for long periods, which causes the same herbs to be grazed repeatedly, particularly during spring $(6,9)$. Under low to moderate grazing pressure on key species, palatable grasses and forbs decrease in abundance relative to sagebrush. Given time, sagebrush eventually dominates the landscape 
as grasses and forbs are grazed at ever increasing rates relative to sagebrush. The same scenario is occurring in ecosystems worldwide (44).

Herbivores must consume enough to meet their nutritional needs and simultaneously avoid overingesting too much of any particular nutrient or toxin. In so doing, they affect the dynamics of vegetation. We can make four generalizations about these relationships (44): (1) nutrient and toxin satiation limit biomass intake, (2) the mass of a plant chemotype (the biochemical characteristic of a forage) that an animal can consume is usually insufficient to meet daily requirements for energy and protein, (3) a mixed diet is essential to meet nutritional needs and avoid poisoning, and (4) the impact of herbivory on a particular chemotype varies with the total available biomass of that species.

Herbivores satiate on nutrients and toxins, and that influences the intake of plants (46). According to the satiety hypothesis, toxic plants should be least utilized when neighboring plants have one or more of the following characteristics: low levels of nutrients needed to mitigate toxicosis, high levels of nutrients that interact adversely with toxins, or toxins that are not complementary (44). If a plant assemblage supplies appropriate nutrients, the threshold of toxin satiation will increase, which is consistent with the high levels of herbivory experienced by toxic plants that constitute a minor proportion of a nutritious diet. As a toxic plant becomes more abundant and the availability of nutrients declines, toxin-satiation thresholds and utilization will both decline. Thus, use of a plant may increase or decrease without any change in its toxin content.

These interactions are affected by the abundance of different plant chemotypes in a mix because nutrient-toxin interactions satiate herbivores at critical upper and lower thresholds of plant abundance (44). Above these thresholds, herbivory will favor domination by a chemotype as others are eaten at ever increasing rates. Below these thresholds, local extinction is more likely as a species becomes increasingly less abundant. Thus, plants with less effective chemical or physical defenses can reach "thresholds of escape" at increasing levels of abundance, just as plants with more effective defenses can be reduced or eliminated at lower levels of abundance. Collectively, these interactions set the asymptotes of functional responses that affect the population dynamics of plants and herbivores. Paradoxically, these interactions are influenced by management based on the notions of key species and moderate grazing, yet focusing on a key species can actually lead to its demise.

Key Plant Species and Moderate Grazing - Many forms of management are based on the assumption that moderate grazing will maintain decreasers in a plant assemblage. These notions, summarized by Holechek et al., maintain: "Key management species are those on which management of grazing on a specific range is based. The key species and key area serve as indicators of management effectiveness. Generally, when the key species and key area are considered properly used, the entire pasture is considered correctly used... In most cases one to three plant species are used as key species. These plants should be abundant, productive, and palatable... Key species are usually decreaser plants that are an important part of the climax vegetation. If the range has been heavily grazed, decreasers may be in short supply but they have the potential to become abundant if grazing pressure is reduced... Under the key-species approach, secondary forage species...will receive light use (10\% to $25 \%)$, key species...will receive moderate use ( $30 \%$ to $40 \%$ ), and the ice-cream plants...may be used excessively (over 40\%)."

However, by focusing attention on decreasers we ever so slowly facilitate animals eating their way out of house and home, and the problem is exacerbated by our obsession with high rates of animal gain (34). Even our best attempts to favor decreasers may inadvertently provide competitive advantages to secondary species that will eventually come to dominate if they are not used by herbivores (63). Conversely, management that makes use of all plant species can enhance biodiversity. For instance, spring use of rangelands by cattle following winter use by mule deer is good for cattle and deer, but exclusive use by one species or the other leads to long-term changes in vegetation that eventually cause the demise of one species or the other (1). Unfortunately, our culturally conditioned biases tend to favor one animal species to the long-term detriment of the other.

It is strange indeed that focusing on one facet of a system leads to the demise of the facet of the system we wish most to sustain. As Holling points out 
"The very success in managing a target variable for sustained production of food or fiber apparently leads inevitably to an ultimate pathology of less resilient and more vulnerable ecosystems, more rigid and unresponsive management agencies, and more dependent societies." Our focus on key species may lead inevitably to their demise.

Ironically, we should focus grazing management on increaser species to maintain the abundance of decreaser species. This idea, while fairly obvious, has not been given due consideration in grazing management or in studies of how drought and defoliation interact to influence the abundance of increasers and decreasers. Most grazing studies are far too short ( 3 to 5 years, 10 years maximum) to observe these delayed effects. Even less obvious than ecological shifts in response to grazing strategies is the influence of grazing practices on the learned behaviors of herbivores during their lifetime and across generations $(46,58)$. By encouraging use of ice cream and decreaser species, might we inadvertently train animals to eat the best and leave the rest rather than to mix the best with the rest, thereby creating herbivore cultures that behave in ways counter to what we desire?

\section{Herbivore Culture and Grazing Management}

Our science and management of the past 25 years have both assumed that herbivores "just know" what and what not to eat and where and where not to go to forage. We have also been taught that herbivores optimize their use of foods and habitats (53). While this is undoubtedly true, we have not understood how herbivores come to optimize and equally important, how past experiences influence optimization. Thus, it is ironic that even with our current understanding of herbivore optimization and new ways of managing grazing we are baffled when animal performance declines despite an abundance of suitable habitats and nutritious forages $(27,40)$. And our emphasis on managed grazing based on technology, while solving one set of problems, has created others: Why have we come to rely so heavily on fences and grazing systems to manage livestock when vast herds of wild herbivores apparently did so for eons without the help of humans $(9,54)$ ?

The Overlooked Role of Herbivore Learning and Culture - Researchers and managers typically con- sider foraging only in terms of how the physical and chemical characteristics of plants influence an animal's ability to achieve high rates of intake. The social environment is rarely considered. This is an unfortunate oversight because socializing with mother and peers helps young animals learn about every facet of the environment from the locations of water and cover to the kinds and locations of nutritious and toxic foods to hazards such as predators. These interactions have a lifelong influence on what an animal eats and where it goes.

The impact of social learning on adaptation helps account for why herbivores of the same species can be found in very different environments and can survive on radically different foods $(40,46)$. A young herbivore learns what kind of creature it will be through social interactions. A calf reared in shrub-dominated deserts of southern Utah is different from a calf reared on grass in the bayous of Louisiana. A bison reared on shrub-dominated ranges in Alaska is different from a bison reared on grasslands in Montana. We typically consider cattle, elk, and bison to be grazers, and goats, deer, antelope, and sheep to be forb eaters and browsers. However, "grazers" can live nicely on diets of shrubs, and "browsers" can survive primarily on grass if they learn to do so.

Learned adaptations for how to live in local environments mean that changes in management require animals to learn new patterns of behavior, which can decrease performance - body weight and condition, as well as conception rates - for 1 to 3 years (40). Jim Howell makes this point in Cows Have Culture Too Understanding Livestock/Landscape Interactions: "For those of us managing ranches holistically, this whole issue of livestock culture has huge implications as we begin to plan our grazing and develop our ranch infrastructure. In my opinion, it goes a long way to explaining why so many of us have struggled as we transition to planned grazing. If we can understand the components of culture and more deeply appreciate the ways that animals interact with their environments, I think we might be able to smooth out these discouraging curves."

Once mastered, behavioral principles and practices provide an array of solutions to the problems people face in managing to improve the integrity of the land and to make a living from the land (40). Unlike the infrastructure of a ranch such as corrals, 
fences, and water development, behavioral solutions cost very little to implement and they are easily transferred from one situation to the next. Unfortunately, scientists and managers often ignore the power of behavior to transform systems, despite compelling evidence. We know the environment, continually interacting with the genome during the growth and development of an organism, creates behavioral responses (46). Though experiences during development in utero and early in life are especially critical, genome-environment interactions continue throughout life. Thus, the issue isn't if animals are adapting to ongoing changes in social and physical environments - they do so every day of their lives. The only question is whether or not people want to be a part of that process. Paradoxically, we influence behavior with what we do and with what we don't do. For those willing to understand how environments interact with the genome to influence behavior, the potential is virtually unlimited.

Using Understanding of Herbivore Culture to Manage Grazing - Herbivores learn to eat foods that differ in concentrations of nutrients and toxins in a manner consistent with their previous experiences with the mix of foods offered (58). If allowed to eat only the most preferred plants, herbivores may not learn how to mix foods high in nutrients with foods that contain toxins. On the other hand, herbivores repeatedly pressured to eat part of all the plants in an area may learn to eat mixtures of nutritious and toxic plants in ways that mitigate toxicity.

This leads to the hypothesis that different systems of grazing management cause animals to forage in different ways (46). Assuming appropriate stocking rates, low stock densities for extended periods of time are likely to encourage selective foraging and re-grazing of individual plants, whereas high stock densities for short periods are likely to encourage diet mixing. If so, what was traditionally considered proper grazing management - rotational grazing at low stock densities - may have trained generations of livestock to use foods and habitats selectively (eat the best and leave the rest) thus inadvertently accelerating a decline in plant diversity and an increase in abundance of less desirable plant species. Conversely, high stock densities for short periods may train animals to use a broader array of foods and habitats (mix the best with the rest).

This notion is based on three assumptions. First, the availability of foods is such that animals can eat foods that are biochemically complementary, and thus mix their diets in ways that facilitate eating plants that contain toxins. Secondly, "forcing animals to eat all of the foods" involves training them through increasing stock density to eat a broader array of foods. Animals will voluntarily eat more of foods that contain toxins, and even gain more weight, if they also learn to eat a variety of sub-optimal foods that are biochemically complementary, to minimize the impact of toxins and increase the intake of nutrients $(46,58)$. Animals who have learned to eat such an array of foods may continue to do so, even if they no longer graze at high stock densities. This view is not compatible with the idea of a linear relationship between stocking rate and animal performance, given the changes in performance that may occur if animals learn to eat complementary mixtures of plants. Finally, more even utilization of all plants for short periods enhances the ability of plants to regrow and minimizes the competitive advantages that occur for plants not grazed (6).

The crucial question is: Do high stock densities cause animals to learn different patterns of foraging behavior? There is evidence to support this hypothesis. For example, Ray Banister, who manages 7,200 acres of land in eastern Montana, has modified his grazing management from reliance on rotational grazing to boom-bust grazing involving intense periods of grazing during the growing season followed by two growing seasons of rest $(40,46)$. Such intense grazing ensures that less palatable and weedy plants do not acquire a competitive advantage over more palatable species. The ranch has some of the highest vegetation cover and diversity in eastern Montana (Joe Fidel, Natural Resource Conservation Service, personal communication). The change from rotational to boom-bust grazing meant cattle could no longer select only the most preferred plants. Based on cow and calf performance, it took 3 years for Ray's cattle to adapt to the new grazing regime. Weaning weights of calves dropped from over 500 pounds to 350 pounds before rebounding to over 500 pounds. During that time, cows learned to eat shrubs such as snowberry and sagebrush, which are usually considered unpalatable due to their levels of toxins, and they evidently learned to eat palatable and unpalatable 
species simultaneously to mitigate the aversive effects of toxins.

Such learned patterns of behavior are likely to be transmitted from mothers to their offspring ( 3,21 , $33,55)$, resulting in cultures that enhance biodiversity and benefit soils, plants, and animals. A culture develops when practices that originate this way contribute to the group's success at solving problems $(52,59)$. Cultures evolve as individuals in groups discover new ways of behaving - as with finding new foods or habitats or better ways to select a nutritionally balanced diet. In herbivores, social organization leads to culture, which is the collective knowledge and habits acquired and passed from generation to generation about how to survive in a particular environment. It is the process whereby young animals learn through their parents from their ancestors, and in which new behaviors learned by any member of the group - young and old alike are passed from generation to generation. Finally, it is a process through which herbivore cultures unique to each landscape can influence in different ways the structure and functioning of particular ecosystems $(43,44,45,46)$.

Unfortunately, social organization and culture are rarely considered important in the structuring and functioning of ecosystems, and indeed we manage wild and domestic animals in ways that thwart the development of cultures perhaps to our long-term detriment $(16,46)$. If instead we were to allow cultures to evolve, we may lessen our need for technological fixes and come to rely more on low-cost behavioral solutions to the challenges we face in managing ecosystems (40). In the process, both our science and management would come to appreciate the processes that unite cultures and ecosystems. Such knowledge is likely to be invaluable for those who aspire to manage wild and domestic animals in ways that maintain the integrity of the animals and the land.

With domesticated livestock, we have come to rely on fences and grazing systems rather than culture to influence diet and habitat selection (46). Interestingly, social organization in herbivores may lead to rotational grazing without fences (40). This notion is based on four assumptions: (1) social herbivores live in extended families, (2) maintaining the cohesiveness of families and their home ranges influences behavior, (3) individuals within families differ in their preferences for foods and habitats, and (4) families maintain their unique identities by avoiding prolonged contact with other families. If these assumptions are correct, then social interactions within families are likely to encourage animals to eat a broader array of plants and to forage in a greater variety of locations as individuals maintain the cohesiveness of the group and respond to different preferences of individuals within the group. Interactions among families are likely to further increase movements across landscapes as different families avoid prolonged contact with one another. Hence, diet and habitat breadth both may increase through social organization, and culture may be critical for maintaining the integrity of social species and the biodiversity of landscapes.

If valid, these hypotheses have far-reaching implications. Historically, social species such as bison played a central role in the structuring and functioning of ecosystems, and there is an opportunity for social species including domestic livestock and bison to play a similar role today (56). To best realize this goal, we must understand not only how behavior is influenced by modern grazing management techniques - strategic placement of water, salt, fences - we must also understand how social organization and culture influence use of landscapes.

\section{Upshot: From Death Comes Life and Endless Transformation}

This glance back at the past quarter century accents our ever-changing understanding of plant-herbivore interactions and their inflections in grazing management, illustrates the paradoxes we confront, and shows how their ongoing resolution plays an integral role in science. As twentieth-century physics has shown, there is no absolute truth in science, all concepts and theories are limited and approximate. Science is a quest for understanding, for truth, an attempt to account for observable phenomena, but science cannot be perceived as "true" or "final" in any absolute sense. It is merely a tentative organization of working hypotheses that, for the moment, best account for the facts concerning biophysical processes whose interconnections are the fabric of a web characterized by change. Even more paradoxical than our ever changing scientific understanding is our apparent inability to manage in ways that are sustainable: How does one manage ongoing 
interrelationships among facets of complex, wholly interconnected, poorly understood, ever changing ecological, cultural, and economic systems, in light of a future not known and not necessarily predictable, in ways that will not diminish options for future generations?

Perhaps in our quest to concretize - to understand and to manage sustainably - we miss the point. Perhaps, we live in a biosphere that as Stuart Kauffman argues in Investigations "is doing something literally incalculable, nonalgorithmic, and outside our capacity to predict, not due to quantum uncertainty alone, nor deterministic chaos alone, but for a different, equally, or more profound reason: Emergent and persistent creativity in the physical universe is real." Perhaps the notions of death and resurrection, common in mythologies from throughout time, are the essence not only of plant-herbivore interactions, but of existence in the biosphere and the cosmos $(10,11,30)$.

If so, then as Kauffman surmises in At Home in the Universe "...the fate of all complex adapting systems in the biosphere - from single cells to economies - is to evolve to a natural state between order and chaos, a grand compromise between order and surprise. Here at this poised state, small and large avalanches of coevolutionary change propagate through the system as a consequence of the small, best choices of the actors themselves, competing and cooperating for survival...on small and large scales, we all do the best we can but will eventually be hustled offstage by some unanticipated consequence of our own best efforts."

So, in the process of exploiting existing niches, new niches are created by the players themselves, each cooperating and competing in their quest to survive. On small and large scales, each thing - organisms in ecology, institutions in society, technologies in economies - in its pursuit of a place in the sun, a niche, sows the seeds that ultimately lead to its demise. There is no denying that fact for social organizations, technologies, and economies. The mean lifetime of a Fortune 500 company is less than half our lifetime, and most companies live very much less - typically no more than 5 years $(50,51)$. The fate of species in the biosphere is no better: greater than $98 \%$ of all that have ever lived are extinct. And the fate of individuals? Well, they're all gone.

This philosophical concept is not new. Ages ago, the Buddha taught that "all compounded things are impermanent" and the Sutras advised "Like a star, an optical illusion, or a flame, A magical illusion, a dewdrop, or a bubble, Like a dream, a flash of lightning, or a cloud - So should one consider all compounded things." The Dalai Lama instructs "Since everything arises complete from the outset, the birth of things comes together with the seed or potential for their dissolution." $(14,15)$. No, the notion is not unprecedented but it is hard to accept that we are all weeds on our way to extinction. We are actors on stages we help to create, vying for roles we hope in vain to preserve. In the short term we endeavor to maintain that which in the long term is impossible to sustain.

So what is one to do? Give up in despair? Certainly not. The challenge is to learn to accept the world as it moves and changes - to play the game. And one way to play the game, perhaps the only way to persist for any length of time, is to open up to others of disparate beliefs - to integrate social, biophysical, and economic values of peoples from vastly different backgrounds. In that sense, "love your enemies" has very practical implications. By so doing, we increase the likelihood of managing in ways that consider more than one "target variable" and thus maximize the diversity of options upon which to act. This is consistent with Stuart Kauffman's thesis that life co-evolves to a liquid phase - "edge of chaos" - between too rigid (ice) and too fluid (gaseous) behavior; in the process, we and all other creatures forever push our way into novelty - molecular, morphological, behavioral, organizational. Life is an odd blend of tradition and innovation, curiosity and caution: "smart" entities that survive for long find a balance between the two, while those who are too cautious (frozen) or too curious (gaseous) quickly go extinct.

By interacting with others of disparate backgrounds, we can also create crucial blends in science and management. Ever increasing scientific understanding of nature combined with management innovations based on scientific principles can help us to maintain fluidity, but we typically do not integrate among diverse scientific disciplines or between science and management. As Stuart Kauffman writes in Investigations "We have thought in part, that the unfolding of society and culture could be brought under the sway of science. On the other hand, Sun Tzu, Four centuries prior to 
Christ, and Clausewitz, in the early nineteenth century, in, respectively, The Art of War and On War, both stressed the totally unexpected ways of battle and the need for intuition and command genius, whatever the science lying behind strategy and tactics. Science and art - the practical getting on with it, wissen versus konnen in German, "know that" versus "know-how" in English, mingle in our daily lives. Yet konnen, "know-how" has no place in our science. Why?"

We need more than ever a blend of know-that and know-how in the science of plant-herbivore interactions and art of grazing management. That blend will help us all to better appreciate how history, necessity, and chance influence the behavior of ecological, cultural, and economic systems, and how we can use that understanding to manage everevolving ecosystems $(43,45,46)$. Ultimately, seemingly paradoxically, creativity comes from the union of pairs of opposites, as each polarity ceaselessly dies to itself and resurrects anew (39).

\footnotetext{
About the Author: Frederick Provenza is a professor with the Department of Forest, Range and Wildlife Sciences, Utah State University; Logan.
}

\section{References}

1. Austin, D.D. 2000. Managing livestock grazing for mule deer (Odocoileus hemionus) on winter range in the Great Basin. Western N. Am. Nat. 60:198-203.

2. Bingham, S. 1996. The Last Ranch: A Colorado Community and the Coming Desert. Harcourt Brace \& Company. New York, N.Y.

3. Biquand, S. and V. Biquand-Guyot. 1992. The influence of peers, lineage and environment on food selection of the criollo goat (Capra hircus). Appl. Anim. Behav. Sci. 34:231-245.

4. Bork, E.W., N.E. West, and J.W. Walker. 1998. Cover components on long-term seasonal sheep grazing treatments in three-tip sagebrush steppe. J. Range Manage. 51:293-300.

5. Bradford, D., J. McConkey, and F. Reed. 2003. A range management review. Rangelands 25:3-12.

6. Briske, D.D. and J.H. Richards. 1995. Plant responses to defoliation: A physiological, morphological and demographic evaluation. Pages 635-710 in D.J. Bedunah and R.E. Sosebee (eds.) Wildland Plants: Physiological Ecology and Developmental Morphology. Soc. Range Manage., Denver, Colorado.

7. Bryant, J. P. and P.J. Kuropat. 1980. Selection of winter forage by subarctic browsing vertebrates: The role of plant chemistry. Ann. Rev. Ecol. Syst. 11:261-285.
8. Bryant, J.P., F.S. Chapin III, and D.R. Kline. 1983. Carbon/nutrient balance of boreal plants in relation to vertebrate herbivory. Oikos 40:357-368.

9. Burkhardt, J.W. 1996. Herbivory in the Intermountain West. Idaho Forest, Wildlife and Range Experiment Station Bulletin 58. Moscow, Idaho.

10. Campbell, J. 1988. Myths to Live By. Viking Penguin Inc., New York, N.Y.

11. Campbell, J. and B. Moyers. 1988. The Power of Myth. Doubleday, New York, N.Y.

12. Capra, F. 1982. The Turning Point: Science, Society, and the Rising Culture. Bantam Books, New York, N.Y.

13. Coley, P.D., J.P. Bryant, and F.S. Chapin III. 1985. Resource availability and plant antiherbivore defense. Science 230:895-899.

14. Dalai Lama 1999. Ethics for the New Millennium. Penguin Putman, Inc. New York, N.Y.

15. Dalai Lama 2002. How to Practice: The Way to a Meaningful Life. Simon \& Schuster, Inc. New York, N.Y.

16. Engel, C. 2002. Wild Health: How Animals Keep Themselves Well and What We Can Learn from Them. Houghton Mifflin Co., New York, N.Y.

17. Foley, W.J., G.R. Iason, and C. McArthur. 1999. Role of plant secondary metabolites in the nutritional ecology of mammalian herbivores: How far have we come in 25 years? Pages 130-209 in H.G. Jung and G.C. Fahey, Jr. (eds.) Nutritional Ecology of Herbivores. Proc. Vth Int. Symp. Nutr. Herb. Am. Soc. Anim. Sci., Ill.

18. Freeland, W.J. and D.H. Janzen. 1974. Strategies in herbivory by mammals: The role of plant secondary compounds. Am. Nat. 108:269-289.

19. Gerrish, J. 2003. The Missouri grazing experience: lessons learned. Pages 10-13 in Heart of America Grazing Conference. Natural Resource Conservation Service. Houston, Missouri.

20. Gerrish, J. and C. Roberts. 1999. Missouri Grazing Manual. MU Extension. Univ. Missouri-Columbia, Missouri.

21. Green, G.C., R.L. Elwin, B.E. Mottershead, and J.J. Lynch. 1984. Long-term effects of early experience to supplementary feeding in sheep. Proc. Aust. Soc. Anim. Prod. 15:373-375.

22. Hay, M.E. and W. Fenical. 1988. Marine plant-herbivore interactions: The ecology of chemical defense. Ann. Rev. Ecol. Syst. 19:111-145.

23. Heitschmidt, R.K. and J.W. Stuth (eds.). 1991. Grazing Management: An ecological Perspective. Timber Press. Portland, Ore.

24. Hofmann, R.R. 1988. Anatomy of the gastrointestinal tract. Pages 14-43 in Church, D.C. (ed.) The Ruminant Animal. Prentice Hall, Englewood Cliffs, N.J. 
25. Holechek, J.L., R.D. Piper, and C.H. Herbel. 2001. Range Management: Principles and Practices. Prentice Hall, Upper Saddle River, N.J.

26. Holling, C.S. 1995. What Barriers? What Bridges? Pages 3-34 in L.H. Gunderson, C.S. Holling, and S.S. Light (eds.) Barriers \& Bridges to the Renewal of Ecosystems and Institutions. Columbia Univ. Press, N.Y.

27. Howell, J. 2002. Cows have culture too - Understanding livestock/landscape interactions. In Practice, March/April.

28. Illius, A.W. and J. Hodgson. 1996. Progress in understanding the ecology and management of grazing systems. Pages 429-457 in J. Hodgson and A.W. Illius (eds.) The Ecology and Management of Grazing Systems. Commonwealth Agricultural Bureau International, Wallingford, U.K.

29. Kauffman, S.A. 1995. At Home in the Universe: A Search for the Laws of Self-Organization and Complexity. Oxford University Press, New York, N.Y.

30. Kauffman, S.A. 2000. Investigations. Oxford University Press, New York, N.Y.

31. Laca, E., L.A. Shipley, and E.D. Reid. 2001. Structural anti-quality characteristics of range and pasture plants. J. Range Manage. 54:413-419.

32. Launchbaugh, K.L., F.D. Provenza, and J.A. Pfister. 2001. Herbivore response to anti-quality factors in forages. J. Range Manage. 54:431-440.

33. Mirza, S.N. and F.D. Provenza. 1990. Preference of the mother affects selection and avoidance of foods by lambs differing in age. Appl. Anim. Behav. Sci. 28:255-263.

34. Norton, B.E. 2003. Spatial management of grazing to enhance both livestock production and resource condition: a scientific argument. Pages 810-820 in N. Allsopp, A.R. Palmer, S.J. Milton, G.I.H. Kerley, K.P. Kirkman, C.R. Hurt, and C.J. Brown (eds.) Proceedings VII th International Rangeland Congress. Durban, South Africa.

35. Pollan, M. 2001. Power Steer. New York Times Magazine. March 31.

36. Provenza, F.D. 1995. Postingestive feedback as an elementary determinant of food preference and intake in ruminants. J. Range Manage. 48:2-17.

37. Provenza, F.D. 1995. Tracking variable environments: There is more than one kind of memory. J. Chem. Ecol. 21:911-923.

38. Provenza, F.D. 1996. Acquired aversions as the basis for varied diets of ruminants foraging on rangelands. J. Anim. Sci. 74:2010-2020.

39. Provenza, F.D. 2000. Science, myth, and the management of natural resources. Rangelands 22:33-36.

40. Provenza, F.D. 2003. Foraging Behavior: Managing to Survive in a World of Change. Utah State Univ. Logan, Utah.

41. Provenza, F.D. and J.C. Malechek. 1984. Diet selection by domestic goats in relation to blackbrush twig chemistry. J. Appl. Ecol. 21:831-841.
42. Provenza, F.D., J.A. Pfister, and C.D. Cheney. 1992. Mechanisms of learning in diet selection with reference to phytotoxicosis in herbivores. J. Range Manage. 45:36-45.

43. Provenza, F.D., J.J. Villalba, and M. Augner. 1999. The physics of foraging. Volume III, Pages 99-107 in J.G. Buchanan-Smith, L.D Bailey, and P. McCaughey (eds.) Proceedings of the XVIII International Grassland Congress. Extension Service, Saskatchewan Agriculture \& Food. Saskatoon, Saskatchewan.

44. Provenza, F.D., J.J. Villalba, and J.P. Bryant. 2002. Foraging by herbivores: Linking the biochemical diversity of plants with herbivore culture and landscape diversity. Pages 387-421 in J.A. Bissonette and I. Storch (eds.) Landscape Ecology and Resource Management: Linking Theory with Practice. Island Press, N.Y.

45. Provenza, F.D., J.J. Villalba, C.D. Cheney, and S.J. Werner. 1998. Self-organization of foraging behavior: from simplicity to complexity without goals. Nutr. Res. Rev. 11:199-222.

46. Provenza, F.D., J.J. Villalba, L.E. Dziba, S.B. Atwood, and R.E. Banner. 2003. Linking herbivore experience, varied diets, and plant biochemical diversity. Small Rum. Res. 49:257-274.

47. Rosenthal, G.A. and M.R. Berenbaum (eds.). 1992. Herbivores: Their Interactions with Secondary Plant Metabolites. Second Ed. Academic Press, New York, N.Y.

48. Rosenthal, G.A. and D.H. Janzen (eds.). 1979. Herbivores: Their Interaction With Secondary Plant Metabolites. Academic Press, New York, N.Y.

49. Savory, A. and J. Butterfield. 1999. Holistic Management: A New Framework for Decision-Making. Second Edition, Island Press, Covalo, Calif.

50. Senge, P.M. 1990. The leader's new work: building learning organizations. Sloan Management Review 32:7-23.

51. Senge, P.M. 1994. The Fifth Discipline: The Art and Practice of the Learning Organization. Doubleday, N.Y.

52. Skinner, B.F. 1981. Selection by consequences. Science 213:501-504.

53. Stephens, D.W. and J.R. Krebs. 1986. Foraging Theory. Princeton University Press, Princeton, N.J.

54. Stoddart, L.A., A.D. Smith, and T.W. Box. 1975. Range Management. McGraw-Hill, New York, N.Y.

55. Thorhallsdottir, A.G., F.D. Provenza, and D.F. Balph. 1990. Ability of lambs to learn about novel foods while observing or participating with social models. Appl. Anim. Behav. Sci. 25:25-33.

56. Truett, J.C., M. Phillips, K. Kunkel, and R. Miller. 2001. Managing bison to restore biodiversity. Great Plaines Res. 11:123-144.

57. Van Soest, P.J. 1982. Nutritional Ecology of the Ruminant. Corvallis, Ore.

58. Villalba, J.J., F.D. Provenza, and GouDong. 2003. Implications of plant chemistry and herbivore learning for diet mixing and plant biochemical diversity. Oikos in press. 
59. Waal, F. de. 2001. The Ape and the Sushi Master: Cultural Reflections of a Primatologist. Basic Books, New York, N.Y.

60. West, N. E. 1993. Biodiversity of rangelands. J. Range Manage. 46:2-13.

61. West, N.E. 1999. Juniper-pinon savannas and woodlands of western North America. Pages 288-308 in: Anderson, R.C., J.S. Fralish and J.M. Baskin (eds.) Savannas, Barrens, and Rock Outcrop Plant Communities of North America. Cambridge University Press, New York, N.Y.
62. West, N.E. and J.A. Young. 2000. Intermountain valleys and lower mountain slopes. Pages 256-284 in: Barbour, M.G. and W.D. Billings (eds.) North American Terrestrial Vegetation. $2^{\text {nd }}$ ed. Cambridge Univ. Press, New York, N.Y.

63. West, N.E., F.D. Provenza, P.S. Johnson, and M.K. Owens. 1984. Vegetation change after 13 years of livestock grazing exclusion on sagebrush semi-desert in central Utah. J. Range Manage. 37:262-264.

64. Wilmshurst, J.F., J.M Fryxell, and R.J. Hudson. 1995. Forage quality and patch choice by wapiti (Cervus elaphus). Behavioral Ecology 6:209-217.

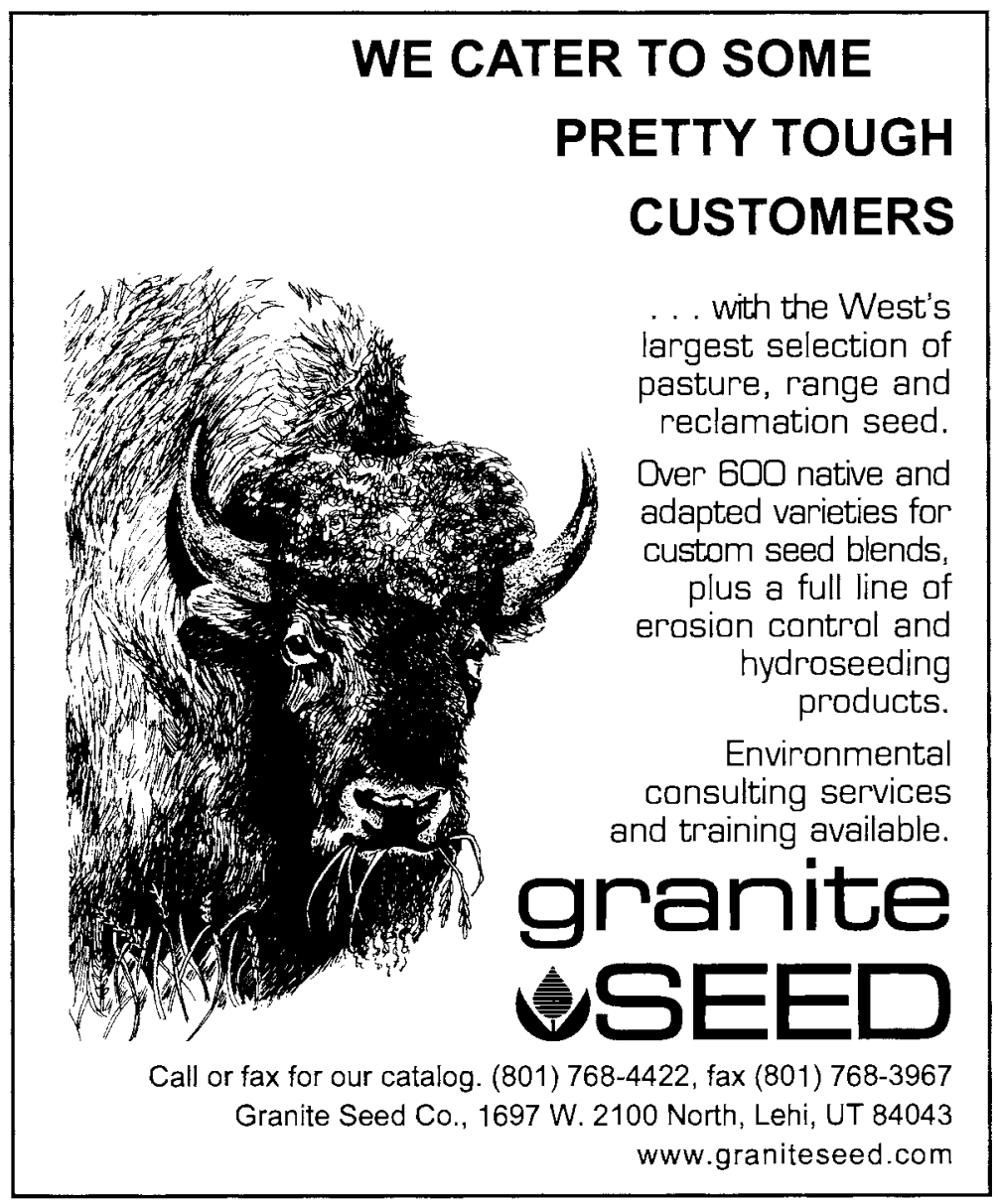

